\title{
COMMENTARY: EATING DISORDERS AND THE PROBLEM OF "CULTURE" IN ACCULTURATION
}

The papers in this issue grapple with a conundrum: what should we make of the fact that eating disorders, long considered to be the consummate culturebound syndrome of Western (post) industrial modernity, seem to be on the rise in purportedly "non-Western" or "non-modern" contexts across the globe? Before turning to the specifics of how the articles speak to this question, I would like to sketch, in minimalist fashion, an outline of the broader conceptual backdrop against which they should be read.

The most common explanation in the scholarly literature for the appearance of eating disorders in unexpected places is that they are a result of the "Westernization" or "modernization" of the society in question (cf. Gunewardene et al. 2001; Lake et al. 2000; Littlewood 1995; Nasser et al. 2001; Stice et al. 1994). The basic proposition here is that as societies become more Western or more modern (or both, as the two are generally seen to be linked), the specific behaviors associated with eating disorders (e.g., self-starvation, bingeing and purging, body image disturbances, intense fear of gaining weight) become meaningful expressions of particular cultural features: heightened consumerism, media saturation, an ethos of independence, and an idealization of self discipline, coupled with the constant seduction to "supersize" everything, from fries to TVs to SUVs. From this perspective, the appearance of eating disorders in a given society is read as evidence of social change, a clear sign that Westernization and modernization are underway and that individuals in these societies are becoming increasingly acculturated to modern Western values (Chamorro and Florez-Ortiz 2000; Davis and Katzman 1999; Ford et al. 1990; Hall 1995; Jane et al. 1999; Joiner and Kashubeck 1996; Nasser 1986, 1997; Pumariega 1986; Wong and Huang 1999; Yoshimura 1995).

While at first glance this proposition seems to be well supported by the data, there are a number of significant problems with the causal reasoning here, particularly in the way culture is talked about. First, the measures of acculturation themselves, while interesting and useful, are, perhaps ironically, problematic as bases for making a cultural argument. Contemporary understandings of acculturation vary but are generally consistent with the classic definition proposed by Redfield et al. (1936: 149) as occurring "when groups of individuals having different cultures come into continuous first hand contacts, with subsequent changes

Culture, Medicine and Psychiatry 28: 607-615, 2004.

(C) 2004 Springer Science+Business Media, Inc.

DOI: $10.1007 / \mathrm{s} 11013-004-1071-9$ 
in the original cultural pattern of either or both groups" or "the cultural change that is initiated by the conjunction of two or more autonomous cultural systems" (Barnett et al. 1954: 974). Not only do these definitions suggest culture as something bounded and separable, they also pose acculturation as a linear process, measured from low to high and indicated by such things as language use, clothing preference, generation, length of time in culture, and so forth (Szapocznik et al. 1978). And despite the emphasis on globalization, when put into practice this line of argument also maintains a dual notion of culture as either geographically autochthonous and tethered-Mexicans in Mexico are acculturated to Mexican culture, for example — or as completely detached from geography and context all together-American culture is exportable whole cloth to other places. In other words, there is an implicit proposition in these models of acculturation that other people's culture is directly tied to its place of origin, while "American culture" is transportable, landing and unproblematically taking root in these new contexts.

From an anthropological perspective this view of culture is both overly simplistic and empirically incorrect. It is not that the conclusions of these studies linking eating disorders and certain cultural values are necessarily "wrong." In fact, it seems reasonable to suspect that eating disorders probably are on the rise in areas around the world other than the industrialized West and that this probably does have something to do with globalization. But these kinds of studies are problematic for suggesting that they actually tell us something useful about the relationship between culture and psychiatric distress when they really do not. Rather, what I think these measures of acculturation and eating disorders get at - and what most researchers mean when they talk about acculturation to Western values - is much more about issues of class and processes of social referencing than about "Culture" (with a big C) per se. This, of course, gets complicated by the fact that, in many parts of the world, purchasing Western products, replicating Western styles, and speaking English are themselves taken as markers of class. But this is part of the point: "culture," whether American, Mexican, Chinese, or whatever, is not separable from the social relationships within which it is realized-social relationships that are conditioned by multiple, sometimes contradictory, values and practices. So while measures of acculturation may indeed measure something, to suggest that they actually measure culture in any meaningful or concrete way is problematic.

This question of what culture is and what it does is the perennial, even the defining, concern of anthropology. Over the past two centuries, this question has generated a range of theories, from Malinowski's functionalism $(1922,1944)$, to Geertz' webs of meaning (1973), to Bourdieu's habitus (1977). More recently, the problem of culture has taken on a different cast, becoming at once both more complex and more urgent in an age of globalization and media saturation. The emergence of the internet, satellite TV and on-demand publishing have broadened, if not necessarily deepened, the scope of human contact, making the exchange of 
ideas, systems of representation, forms of production and actual commodities easier and faster than ever before. This complexity has called for different ways of thinking about culture. Many, following Gramsci's (1971) lead, argue that we should ask not so much what culture is but how certain cultural forms gain prominence and attain ideological force through hegemonic systems (cf. Asad 1993). This subtle but significant shift in focus from the content of culture to the conditions that make certain forms of culture possible has provoked something of a crisis within anthropology about what our subject matter even is and how best to study it.

But while anthropologists may not always agree on what culture is, there is now at least some degree of consensus about what it is not. Most anthropologists today reject earlier formulations of culture as a single, homogenous set of understandings or beliefs that is relatively unproblematically passed on from generation to generation, as well as the notion of culture as both bounded and geographically located (e.g., the culture of India, the culture of Brazil, the culture of Tahiti) (see, e.g., Said 1993, 1995; Appadurai 1996). Yet it is precisely these sorts of understandings that are mobilized in the current scholarly literature on the cultural features of psychic distress, and eating disorders in particular. And in the process, a circular reasoning is often set up wherein the notion of "culture" is injected into psychiatric discourse in a way that serves to bolster existing epistemologies rather than challenge them.

For example, the appearance of eating disorders in other cultures or socioeconomic circumstances would seem to problematize their status as culture-bound syndromes. But instead, this is interpreted as evidence of the exportation of Western culture, of which eating disorders are supposed to be emblematic. There is no traction in this argument. It sets up a system in which eating disorders and Western culture are posited as both evidence of and explanations for one another, while at the same time banking on a notion of culture that, as I have already noted, is both simplistic and empirically incorrect. In this way, culture becomes something of a catchall term for anything not strictly psychological or biological, and as a way of displacing concerns that might otherwise require a more profound examination of the cultural bases of the diagnostic criteria themselves. The effect, presumably unintentional, is an appropriation of the notion of "culture" by scholarly discourse on eating disorders in a way that gives the illusion of cross-cultural substantiation for psychiatric diagnostic criteria, while in fact obscuring genuine cultural analysis. It also at best discounts, and at worst completely ignores, the subjective experience of distress as a meaningful component of analysis.

The corrective for this, of course, is for scholars who take culture seriously to do good, solid, ethnographic research on these issues, so that we can propose constructive alternatives. The papers in this volume represent an important early step in this process, as they struggle to articulate both the messy complexities of lived experience and the pitfalls of theoretical rigidity. Pike and Borovoy, for example, 
question the importance of "Westernization" as the socio-epistemological ground for self-starvation, pointing instead to local Japanese meanings that do not rest on the same sorts of body image and weight concerns found in American women with eating disorders. Becker considers the arrival of global media in Fiji with an eye towards the "gap" between the consumer and the ideal and how this relates to the cultivation of (and resistance to) certain modes of desire. Katzman, Hermans, van Hoeken, and Hoek highlight the importance of examining subgroups within populations in order to tease out how various socio-cultural factors might be differently experienced by individuals living within the same society. Through a consideration of Belizean beauty pageants, Anderson-Fye argues that Belizean girls are more concerned with body shape than body size, and that their anxieties about their bodies therefore do not easily map onto those found among most American girls. And le Grange, Louw, Breen, and Katzman raise the perhaps more fundamental question of the cross-cultural validity of our assessment tools and the kinds of mistakes that can be made when other social factors (such as a real scarcity of food or the likelihood that food might be contaminated) are not considered.

While these papers come at the question I outlined above (how to understand the appearance of a supposedly culture-bound syndrome outside of its cultural context) in very different ways and from very different theoretical and disciplinary perspectives, taken together they highlight some fundamental issues for the crosscultural study of eating disorders and, I would suggest, for any consideration of cultural processes and psychiatric distress. As I read them, we can formulate these issues as three core questions:

1. Are eating disorders (or other psychiatric illnesses) "natural kinds" (Kripke 1980; Putnum 1975)_disease entities with an underlying common nature that exist independently of human cognition, and whose "natural" etiology, symptomotology and course can be identified?

2. If eating disorders are natural kinds, what are the conditions under which they appear and spread?

3. If eating disorders are not natural kinds, how should we best understand the appearance of seemingly similar clusters of symptoms across disparate contexts?

Implicit in these three issues is a fourth, even more fundamental question related to the epistemological commitments of contemporary Western psychiatry:

4. Are psychiatric diagnostic categories objective descriptors of behavior and experience, or do they instead articulate an ethnopsychology whose values are tied to a particular historical and cultural context? 
Although the anthropological literature dealing with this last question is vast (see Castillo 1997; Fabrega 1992; Gaines 1992; Lopez and Guarnaccia 2001 for some excellent critical reviews), the first three tend to run more as a subtext through much of the scholarly literature on eating disorders and have received little explicit attention. In my reading, the papers in this volume are, at least in part, attempts to bridge this gap between critical cultural analysis and descriptive consistency, and suggest the following: Beginning with the fourth question, the answer seems to be yes and yes-yes, psychiatric categories are "objective," in the sense that they are standardized ways of viewing and interpreting human behavior. For example, a common set of understandings of what eating disorders look like enables the authors in this issue to critically discuss similar behavior patterns found in such far-flung places as Japan and Belize. But at the same time, psychiatric categories are "cultural"-inextricably bound up with cultural values about (for example) independence, autonomy, and appropriate gendered experience, and so must always be subject to questioning and critique. It is this perspective that allows for the explorations of how food refusal in South Africa might be phenomenologically distinct from dieting in Fiji.

Turning to the other three core questions, these papers suggest the following provisional responses: Are eating disorders natural kinds? No. Eating disorders might well be one cultural expression of a natural kind that takes other forms, too (for example, the extreme religious asceticism of medieval fasting nuns, who were concerned less with the shapes of their bodies than the purity of their souls). The problem comes when we take one such expression to be the natural kind of which others are variations, when, in fact, we can only know the natural kind itself through its historically and culturally embedded manifestations.

If eating disorders are natural kinds, what are conditions under which they spread? Even if we accept the above proposition that eating disorders are contingent expressions of a natural kind rather than a natural kind themselves, we might still expect that we could identify the conditions under which they might appear and spread. The problem here, as I noted above, is that eating disorders and certain cultural elements tend to be posited as both evidence and explanation for one another, making a truly critical analysis of cause and effect difficult to render. One way of dealing with this tangle is to problematize what is meant by both "eating disorders" and "Western culture," as well as to bracket some of our long-held assumptions about the psychodynamic substrata of eating disorders (e.g., they represent an attempt to regress to childhood dependency, a struggle for individuation, a fear of adult sexuality) as being perhaps as much manifestations of our psychological models as the lived experiences of our clients or subjects. This sort of approach requires an engaged, qualitative research strategy centered on the social and subjective meanings of the experience of self-starvation and how the two interrelate. 
If eating disorders are not natural kinds, how should we understand the appearance of such similar collections of symptoms in such different contexts? This is the fundamental issue at hand. As I see it, there are at least two ways one might answer this question: (1) eating disorders in different contexts are similar (though culturally shaped) expressions of the same underlying disease entity, or (2) they are themselves different disease entities which happen to share some symtomotology. As I noted above, I tend to adopt the former perspective, though I suggest we must remain agnostic at this point as to what, exactly, the underlying syndrome is, since we can only know it through its culturally and historically situated manifestations.

For example, Bordo (1994) argues that eating disorders are crystallizations of the very Cartesian dualism that gave rise to scientific advancement (modernity) and a particular sort of relationship to production (capitalism) — core values of the modern West. But while eating disorders certainly can be read through the lens of Cartesian duality and capitalist ethos, this is not the only framework through which these behaviors might make sense. In fact, one could argue that the separation of self and body reported by many eating disordered women is generally a result (and even the goal, in somewhat Buddhist fashion) of their behavior rather than impetus for it. In other words, the appearance of similar clusters of behaviors in different contexts need not necessarily imply a similar phenomenology.

This brings us back again to the opening question to which each of these papers speaks, though we might now frame it a bit differently: Does the appearance of eating disorders in non-Western, nonmodern contexts around the globe mean that eating disorders are not as "culture-bound" as we thought? Or does it, instead, confirm their embeddedness in modern Western culture? The latter position is perhaps the more comfortable one, as it allows us to shift our analytical gaze to the more macro processes of globalization and modernization. At the same time, it seems to confirm for us that our current understandings of eating disorders are correct - eating disorders must be linked to modern Western culture because they are on the rise in "modernizing" societies. The former position, on the other hand, requires a more critical engagement with our underlying assumptions about what eating disorders are and why people get them. This is more challenging by far, particularly when the theoretical tools we have to think with tend to enfold the very cultural assumptions we wish to question.

Anthropological theories and methods are uniquely suited to navigating these sorts of thorny issues (see, e.g., Banks 1992, 1997; Hsu and Lee 1993; Lee 1996). By combining engaged qualitative research on the phenomenology of self-starvation with critical cultural analyses of the systems through which that phenomenology is articulated and shaped, an anthropologically informed perspective, as the articles here indicate, can lend a fresh and constructive voice to these debates. 
REFERENCES

Appadurai, A.

1996 Modernity at Large: Cultural Dimensions of Modernity. Minneapolis: University of Minnesota Press.

Asad, T.

1993 Genealogies of Religion: Discipline and Reasons of Power in Christianity and Islam. Baltimore: Johns Hopkins University Press.

Banks, C.G.

1992 'Culture' in Culture-Bound Syndromes: The Case of Anorexia Nervosa. Social Science and Medicine 34(8): 867-884.

1997 The Imaginative Use of Religious Symbols in Subjective Experiences of Anorexia Nervosa. Psychoanalytic Review 84(2): 227-236.

Barnett, H.G., B. Siegel, E. Vogt, and J. Watson

1954 Acculturation: An Exploratory Formulation-From the Social Science Research Council Summer Seminar on Acculturation, 1953. American Anthropologist 56: 973-1002.

Bordo, S.

1994 Unbearable Weight: Feminism, Western Culture and the Body. Berkeley: University of California Press.

Bourdieu, P.

1977 Outline of a Theory of Practice. Richard Nice, Trans. Cambridge: Cambridge University Press.

Castillo, R.J.

1997 Culture and Mental Illness: A Client-Centered Approach. Pacific Grove, CA: Brooks/Cole.

Chamorro, R., and Y. Florez-Ortiz

2000 Acculturation and Disordered Eating Patterns Among Mexican American Women. International Journal of Eating Disorders 28: 125-129.

Davis, C., and M. Katzman

1999 Perfection as Acculturation: Psychological Correlates of Eating Problems in Chinese Male and Female Students Living in the United States. International Journal of Eating Disorders 25(1): 65-70.

Fabrega, H.

1992 The Role of Culture in a Theory of Psychiatric Illness. Social Science and Medicine 35(1): 91-103.

Ford, K.A., B.M. Dolan, and C. Evans

1990 Cultural Factors in the Eating Disorders: A Study of Body Shape Preferences of Arab Students. Journal of Psychosomatic Research 34: 501507.

Gaines, A.

1992 From DSM I to DSM III-R; Voices of Self, Mastery, and Other: A Cultural Constructivist Reading of U.S. Psychiatric Classification. Social Science and Medicine 35(1): 3-24.

Geertz, C.

1973 The Interpretation of Cultures: Selected Essays. New York: Basic Books.

Gramsci, A.

1971 Selections from the Prison Notebooks. London: Lawrence and Wishart.

Gunewardene, A., G.F. Huon, and R. Zheng

2001 Exposure to Westernization and Dieting: A Cross-Cultural Study. International Journal of Eating Disorders 29: 289-293. 
Hall, C.C.

1995 Asian Eyes: Body Image and Eating Disorders of Asian and Asian American Women. Eating Disorders 3(1): 8-19.

Hsu, L.K.G., and S. Lee

1993 Is Weight Phobia Always Necessary for a Diagnosis of Anorexia Nervosa? American Journal of Psychiatry 150: 1466-1471.

Jane, D., G. Hunter, and B. Lozzi

1999 Do Cuban American Women Suffer from Eating Disorders? Effects of Media Exposure and Acculturation. Hispanic Journal of Behavioral Sciences 21(2): 212218.

Joiner, Greg W., and Susan Kashubeck

1996 Acculturation, Body Image, Self-Esteem, and Eating-Disorder Symptomatology in Adolescent Mexican American Women. Psychology of Women Quarterly 20(3): $419-435$.

Kripke, S.

1980 Naming and Necessity. Cambridge, MA: Harvard University Press.

Lake, A.J., P.K. Staiger, and H. Glowinski

2000 Effect of Western Culture on Women's Attitudes to Eating and Perceptions of Body Shape. International Journal of Eating Disorders 27(1): 83-89.

Lee, $S$.

1996 Reconsidering the Status of Anorexia Nervosa as a Western Culture-Bound Syndrome. Social Science and Medicine 42(1): 21-34.

Littlewood, R.

1995 Psychopathology and Personal Agency: Modernity, Culture Change and Eating Disorders in South Asian Societies. British Journal of Medical Psychology 68: 45-63.

Lopez, S., and P. Guarnaccia

2001 Cultural Psychopathology: Uncovering the Social World of Mental Illness. Annual Review of Psychology 51: 571-598.

Malinowski, B.

1922 Argonauts of the Western Pacific. New York: Dutton.

1944 A Scientific Theory of Culture. Chapel Hill: University of North Carolina Press.

Nasser, M.

1986 Comparative Study of the Prevalence of Abnormal Eating Attitudes Among Arab Female Students of Both London and Cairo universities. Psychological Medicine 16: 621-625.

Nasser, $\mathrm{M}$.

1997 Culture and Weight Consciousness. New York: Taylor and Francis.

Nasser, M., M. Katzman, and R. Gordon, eds.

2001 Eating Disorders and Cultures in Transition. New York: Brunner-Routledge.

Pumariega, A.J.

1986 Acculturation and Eating Attitudes in Adolescent Girls: A Comparative and Correlational Study. Journal of the American Academy of Child and Adolescent Psychiatry 25: 276-279.

Putnum, H.

1975 Mind, Language, and Reality. Cambridge: Cambridge University Press.

Redfield, R., R. Linton, and M.J. Herskovits

1936 Memorandum for the Study of Acculturation. American Anthropologist 38: $149-152$.

Said, E.

1993 Culture and Imperialism. New York: Knopf/Random House.

1995 Orientalism: Western Conceptions of the Orient. Revised Edition. New York: Penguin. 
Stice, E., K. Schupak-Neuberg, H.E. Shaw, and R.I. Stein

1994 Relation of Media Exposure to Eating Disorder Symptomatology: An Examination of Mediating Mechanisms. Journal of Abnormal Psychology 103: 836-840.

Szapocznik, J., M.A. Scopetta, W. Kurtines, and M. Aranade

1978 Theory and Measurement of Acculturation. Interamerican Journal of Psychology 12: $113-130$.

Wong, Y., and Y. Huang

1999 Obesity Concerns, Weight Satisfaction and Characteristics of Female Dieters: A Study on Female Taiwanese College Students. Journal of the American College of Nutrition 18(2): 194-199.

Yoshimura, K.

1995 Acculturative and Sociocultural Influences on the Development of Eating Disorders in Asian-American Females. Eating Disorders 3(3): 216-228.

\section{REBECCA J. LESTER}

Department of Anthropology

Campus Box 1114

Washington University

St. Louis, MO 63130-4899

E-mail:rjlester@artsci.wustl.edu 